\title{
COVID-19 Among Patients With Hepatitis B or Hepatitis C: A Systematic
}

\section{Review}

\author{
Hossein Mirzaie (iD ${ }^{1}$, Mohammad Vahidi ${ }^{2}$, Mostafa Shokoohi (iD ${ }^{3,1}$, Maryam Darvishian ${ }^{4}$, Hamid \\ Sharifi (iD ${ }^{1}$, Heidar Sharafi i(i) ${ }^{5}$ and Mohammad Karamouzian (i) ${ }^{6, *}$ \\ ${ }^{1}$ HIV/STI Surveillance Research Center, and WHO Collaborating Center for HIV Surveillance, Institute for Futures Studies in Health, Kerman University of Medical Sciences, \\ Kerman, Iran \\ ${ }^{2}$ Faculty of Medicine, Shahid Beheshti University of Medical Sciences, Tehran, Iran \\ ${ }^{3}$ Dalla Lana School of Public Health, University of Toronto, Toronto, ON, Canada \\ ${ }^{4}$ Cancer Control Research, BC Cancer Research Centre, Vancouver, BC, Canada \\ ${ }^{5}$ Middle East Liver Diseases (MELD) Center, Tehran, Iran \\ ${ }^{6}$ School of Population and Public Health, Faculty of Medicine, University of British Columbia, Vancouver, BC, Canada \\ "Corresponding author: School of Population and Public Health, Faculty of Medicine, University of British Columbia, Vancouver, BC, Canada. Email: \\ karamouzian.m@alumni.ubc.ca
}

Received 2020 November 25; Revised 2020 December 19; Accepted 2020 December 29.

\begin{abstract}
Context: Hepatic manifestations of Coronavirus Disease 2019 (COVID-19) are common among people living with Hepatitis B Virus (HBV) and Hepatitis C Virus (HCV).

Objectives: This systematic review aimed to summarize the evidence on COVID-19 patients living with HBV or HCV co-infections.

Data Sources: We searched multiple electronic databases and preprint servers from December 1, 2019, to August 9, 2020.

Study Selection: Studies were included if they reported quantitative empirical data on COVID-19 patients living with HBV or HCV co-infections.

Data Extraction: Descriptive analyses were reported, and data were synthesized narratively. The quality assessment was completed using the Joanna Briggs Institute critical appraisal tools.

Results: Out of the 941 uniquely identified records, 27 studies were included. Of the eligible studies, 232 COVID-19 patients were living with $\mathrm{HBV}$ and 22 were living with HCV. Most patients were male, and the mean age was 49.8 and 62.8 years in patients living with $\mathrm{HBV}$ and HCV, respectively. Among the reported cases of SARS-CoV-2-HBV co-infection, the proportions of death were $4.7 \%$ and $15 \%$ in cross-sectional and case series/report studies, respectively. The death proportion was $8.3 \%$ among the reported cases of SARS-CoV2-HCV co-infection. Among COVID-19 patients, 34.1\% and 76.2\% reported at least one comorbidity besides HBV and HCV infections, mainly hypertension and type 2 diabetes mellitus. The most common COVID-19-related symptoms in both HBV and HCV groups were fever, cough, dyspnea, fatigue, and gastrointestinal symptoms.

Conclusions: While understanding the pathogenesis of SARS-CoV-2 requires further investigations, the careful assessment of hepatic manifestations and chronic infections, such as HBV and HCV upon the admission of COVID-19 patients could help reduce multimorbidity among HBV or HCV patients and lead to more favorable health outcomes among them.
\end{abstract}

Keywords: COVID-19, Hepatitis B, Hepatitis C, Systematic Review

\section{Context}

The first case of Severe Acute Respiratory Syndrome Coronavirus 2 (SARS-CoV-2) infection was reported in China in December 2019 (1). The World Health Organization (WHO) declared Coronavirus Disease 2019 (COVID-19) a pandemic on March 11, 2020. As of October 19, 2020, > 48 million cases and $>1,200,000$ deaths were reported (2). A more severe disease course and a higher mortality rate have been reported in elderly patients, as well as those with underlying conditions, including hyperten- sion, asthma, diabetes mellitus, chronic lung disease, cardiovascular conditions, obesity, and chronic kidney disease (3-8). COVID-19 clinical presentations could vary greatly but often include respiratory, gastrointestinal, renal, and neurological manifestations $(9,10)$.

Recent studies have reported COVID-19 patients presenting with acute hepatitis before demonstrating respiratory symptoms (11). While our understanding of SARSCoV-2 pathogenesis continues to grow, initial studies suggest that the virus could lead to liver injury mainly by binding to Angiotensin-Converting Enzyme 2(ACE2) recep- 
tors on hepatocytes or causing an immune-mediated hepatic injury through cytokine storm activation (12-14). Several studies suggest that COVID-19 could lead to liver injuries and elevated Alanine Aminotransferase (ALT), Aspartate Aminotransferase (AST), and total bilirubin, particularly among severe COVID-19 cases (e.g., those admitted to Intensive Care Unit [ICU]) (15-18). Abnormal liver functions among COVID-19 patients have also been associated with increased disease severity and risk of mortality $(19,20)$. A recent meta-analysis of a few studies on the hepatic manifestations of COVID-19 estimated the pooled prevalence of pre-existing chronic liver disease at 1.9\%, pre-existing liver cirrhosis at $0.4 \%$, HBV at $0.9 \%$, and HCV at $0.3 \%$ (15). While insightful, these findings are limited, as they are only based on less than a handful of small sample-sized studies conducted in China and the USA during the early months of the pandemic (i.e., as late as April 2020)(15). These findings also contradict other earlier studies that reported a significantly higher prevalence of liver complications among COVID-19 patients in China, where 2-11\% of COVID-19 patients had liver comorbidities and up to $54 \%$ had elevated AST and ALT levels (21).

COVID-19-related hepatic complications are of concern, particularly among people living with HCV, HBV, or $\mathrm{HBV} / \mathrm{HCV}$ co-infection with pre-existing liver complications (e.g., cirrhosis, liver failure, hepatocellular carcinoma) $(15,21,22)$. Considering that around 290 million and 71 million people are living with $\mathrm{HBV}$ and $\mathrm{HCV}$, respectively $(23,24)$, the number of patients with SARS-CoV-2 and HBV or $\mathrm{HCV}$ co-infection is likely to increase. Therefore, improving our understanding of the hepatic manifestations and comorbidities among COVID-19 patients living with HBV, HCV, or both is of utmost importance in enhancing the care provided for this large at-risk population.

\section{Objectives}

In this systematic review, we aimed to review and summarize the existing literature on COVID-19 patients living with HBV or HCV comorbidities. The findings of our review could provide information on clinical care and treatment options for COVID-19 patients with these co-infections.

\section{Data Sources}

The inclusion criteria and analytical plan were conceptualized a priori and are documented in the Open Science Framework ( https://osf.io/p4w3j/).

Following the Systematic Reviews and Meta-Analyses (PRISMA) and Peer Review of Electronic Search Strategies (25) guidelines (see Supplementary File S1 for PRISMA checklist), we searched PubMed, Scopus, Web of Science, CINAHL, Embase, and Google Scholar, as well as preprint databases, including medRxiv and bioRxiv from December 1, 2019, to August 9, 2020. Search terms were combined using appropriate Boolean operators and included subject heading terms/keywords relevant to COVID-19 (e.g., SARSCoV-2 or coronavirus disease 2019 or COVID-19 or severe acute respiratory syndrome coronavirus 2 or coronavirus infection) and hepatitis B or C (e.g., liver fibrosis or liver cirrhosis or hepatic transplantation or liver transplant or hepatitis C or hepatitis B or HBV or HCV). Please see Supplementary File S2 for our sample search strategy.

\section{Study Selection}

Quantitative studies of any type (i.e., case report, case series, cross-sectional, case-control, cohort, and clinical trial) that reported individual-level and/or aggregate-level data on COVID-19 patients living with HBV, HCV, or HBVHCV-co-infection were included in this review. Studies that combined the samples of HBV/HCV-positive and HBV/HCVnegative patients were only included if they provided subgroup analyses for people living with $\mathrm{HBV}, \mathrm{HCV}$, or HBVHCV-co-infection. Studies were excluded if they did not present original empirical data or did not report any clinical data for patients. Two reviewers (HM and MV) independently screened all titles, abstracts, and full-texts. Duplicate records were excluded, and disagreements were resolved by discussion or arbitration by the senior author (MK).

\section{Data Extraction}

Data were extracted on a) Study characteristics, including first author, study period, study design, sample size, data type, and study population, b) Sociodemographic characteristics, such as patients' age and sex/gender, c) HBV- and HCV-related characteristics, including cirrhosis status, liver transplantation, received immunosuppressive therapy, and liver enzyme levels (e.g., AST, ALT), d) COVID-19related characteristics, including symptoms and severity of COVID-19 defined as mild (i.e., no or mild pneumonia), severe (i.e., blood oxygen saturation $\leq 93 \%$, dyspnea, or lung infiltrates $>50 \%$ within two days), or critical (i.e., septic shock, respiratory failure, or multiple organ failures) (26). Hospitalization, ICU admission, survival status (recovery or death), and non-hepatic-related comorbidities (e.g., hypertension, diabetes, cardiovascular diseases, Chronic Obstructive Pulmonary Disease [COPD], and malignancies) were also recorded. 


\subsection{Quality Assessment}

Two authors (HM and MV) completed quality assessments independently, using the Joanna Briggs Institute critical appraisal tools (27). These tools assess different items (e.g., selection bias, information bias, and confounding bias) for various study designs, with nine items for case reports, 10 for case series, nine for cross-sectional studies, and 11 for cohort studies.

\subsection{Statistical Analysis}

Descriptive analyses were used for reporting the results. Continuous variables were summarized as mean and Standard Deviation (SD). Categorical variables were summarized by frequencies and percentages. Differences in continuous and categorical variables were compared using the two-tailed student's t-test and Fisher's exact test, respectively. The P values of less than 0.05 were considered statistically significant. For combining data from studies that reported aggregate-level data with those reporting individual-level data, we weighted the aggregate-level data by the number of patients. The proportion of death among reported patients was also measured and reported. The denominator and nominator for this measure were based on patients with HBV or HCV whose COVID-19 was diagnosed and reported. The main findings were stratified by study design. We also conducted a subgroup analysis by patients' receipt of immunosuppressive therapy.

\section{Results}

\subsection{Study Characteristics}

Out of the 941 uniquely identified records, 27 studies met the inclusion criteria and were considered for data extraction. Figure 1 shows the PRISMA flow diagram, and Table 1 presents the study characteristics. Of the 27 included studies with data on SARS-CoV-2 and HBV and/or HCV co-infection, 14 studies reported SARS-CoV-2 and HBV co-infection, 10 studies reported SARS-CoV-2 and HCV co-infection, and three reported both types of coinfection. Regarding their geographical locations, 14 studies reported data from China, three from the USA, two from Spain, two from Brazil, and the remaining six studies from Italy, Austria, Switzerland, the UK, Lithuania, and the UAE (one study each). All of the included studies were observational: 11 studies were case reports, 10 were case series, and six were cross-sectional. The majority of the included studies $(n=21)$ reported individual-level data, and six studies reported aggregate-level data.

\subsection{Participant Characteristics}

As shown in Table1, study populations were diverse and included organ transplant patients (15 studies), people living with HBV and/or HCV (nine studies), cirrhosis patients (two studies), and a diverse group of COVID-19 patients with hepatic comorbidities (one study). Across the 27 studies, 232 SARS-CoV-2 infections were found in patients with HBV and 22 in patients with HCV. Overall, the mean (SD) age was 49.9 (9.7) and 62.8 (10.3) among patients with HBV and $\mathrm{HCV}$, respectively. Most patients in both groups were male (61.6\% among patients with HBV and $72.8 \%$ among patients with $\mathrm{HCV})$.

Among SARS-CoV-2-HBV co-infected patients recruited in cross-sectional studies, no one had a history of liver transplantation or immunosuppressive therapy, and only 3.1\% (five out of 163) had cirrhosis. These conditions, however, were more commonly reported in case series and case reports of SARS-CoV-2-HBV co-infected patients (Table 2). Among SARS-CoV-2-HCV co-infected patients recruited in case series/reports, 95.2\% (20 out of 21) had cirrhosis, and 90.9\% (20 of 22) had a history of liver transplantation and immunosuppressive therapy (Table 3 ).

\subsection{COVID-19-Related Symptoms}

As shown in Table 2 and Table 3, several comorbidities other than COVID-19 and HBV/HCV were reported among the participants. Fever, cough, dyspnea, fatigue, and gastrointestinal symptoms were the most commonly reported COVID-19 symptoms.

Having elevated ALT (i.e., > 45) was found in 22\% (33 out of 150) of patients with SARS-CoV-2-HBV co-infection in cross-sectional studies and $53.8 \%$ (seven out of 13 ) in case series/report studies. In addition, elevated AST (i.e., > 45) was found in $26 \%$ (39 out of 150 ) of patients with SARS-CoV-2HBV co-infection in cross-sectional studies and 30.8\% (four out of 13) in case series/report studies. In patients with SARS-CoV-2-HCV co-infection, 38.5\% (five out of 13 patients) had elevated ALT and AST.

All of the patients in the SARS-CoV-2-HBV co-infected group and $86.4 \%$ (19 of 22) of cases in the SARS-CoV-2-HCV co-infected group were hospitalized. The ICU admission in the SARS-CoV-2-HBV group was reported in 9.8\% (seven of 71 ) of patients in cross-sectional studies and $27.8 \%$ (five of 18 ) in case series/report studies. The ICU admission was reported in $21.4 \%$ of patients in the SARS-CoV-2-HCV group. In the SARS-CoV-2-HBV group, severe COVID-19 symptoms were reported in $39.6 \%$ ( 84 of 212 ) of patients in crosssectional studies and $27.8 \%$ (five of 18 ) in case series/report studies. In the SARS-CoV-2-HCV group, severe COVID-19 symptoms were reported in $21.4 \%$ (three of 14 ) of patients. 


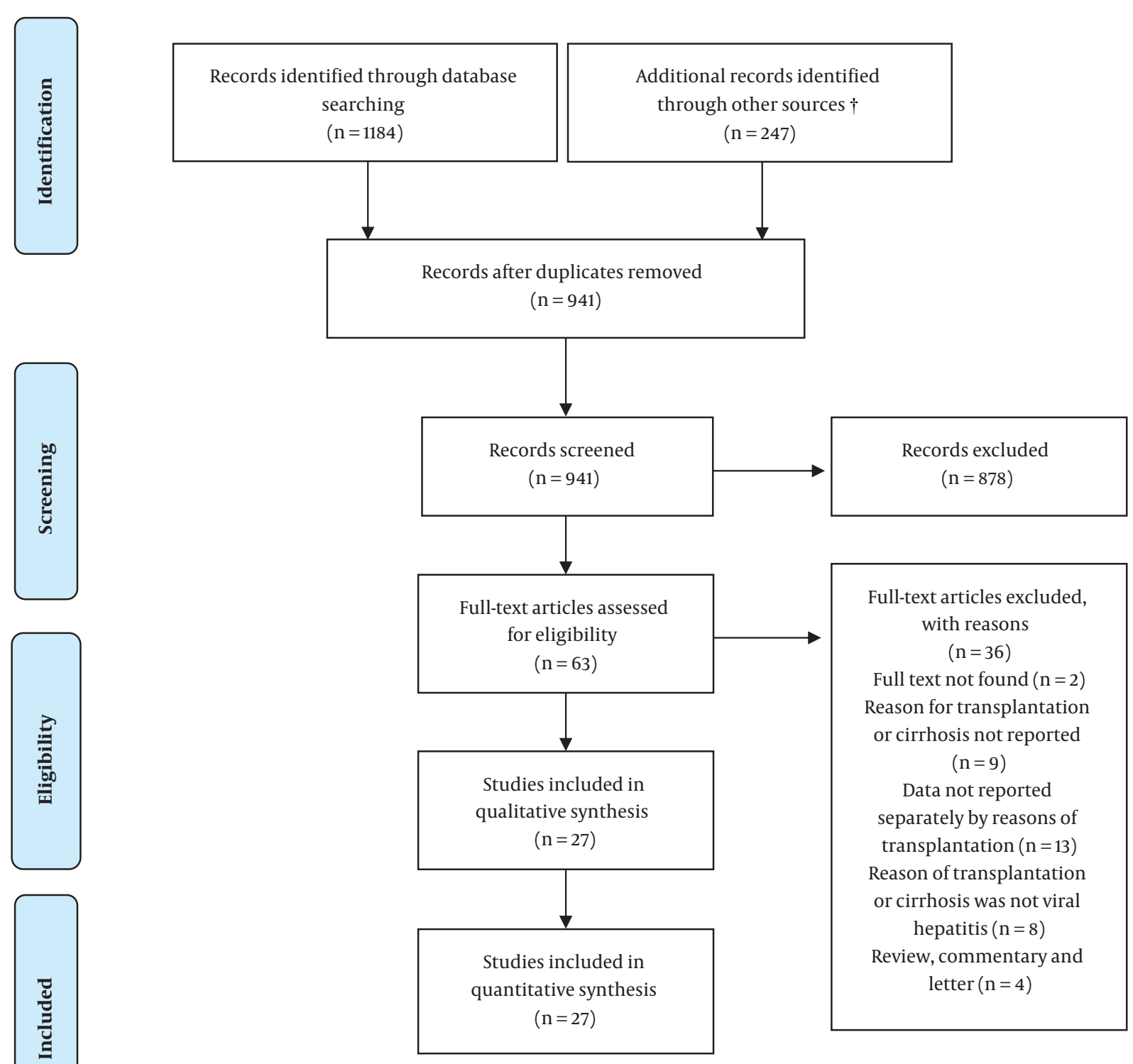

$\dagger$ Other resources included preprint databases (i.e., medRxiv, bioRxiv, Preprints), the references of publications found, and the "cited by" feature of Google Scholar.

\subsection{Death Proportion Among the Patients}

Overall, the death proportions were $4.7 \%$ (10 out of 211) and 15\% (3 out of 20) among SARS-CoV-2-HBV co-infected patients in cross-sectional and case series/report studies, respectively. The three deceased patients in case series/report studies were 73, 53, and 59-years-old and all were males. They had more than one comorbidity, and two of them were on immunosuppressive therapy due to their history of liver transplantation. Information on age and sex of the deceased patients among SARS-CoV-2-HBV co-infected patients in cross-sectional studies was available for two out of 10 patients. Both were male with 38 and 74 years of age.

The proportion of death among SARS-CoV-2-HCV coinfected patients was 8.3 (three of 36). These three patients 
Mirzaie H et al.

\begin{tabular}{|c|c|c|c|c|c|c|c|c|}
\hline First Author & Setting & Study Period $^{\mathrm{a}}$ & Study Design & Data Type & Sample Size & $\begin{array}{c}\text { Type of } \\
\text { Hepatitis }\end{array}$ & $\begin{array}{c}\text { Study } \\
\text { Population }\end{array}$ & $\begin{array}{c}\text { Quality } \\
\text { Assessment }\end{array}$ \\
\hline Aldhaleei (28) & UAE & Not reported & Case report & Individual & 1 & HBV & HBV patient & $7 / 8$ \\
\hline Chen (29) & China & Jan 5 to Feb 20 & Cross-sectional & Aggregate & 15 & HBV & HBV patients & $9 / 9$ \\
\hline Chen (30) & China & Jan 20 to Feb 29 & Cross sectional & Aggregate & 20 & HBV & HBV patients & $8 / 9$ \\
\hline $\begin{array}{l}\text { De Gottardi } \\
\text { (31) }\end{array}$ & Switzerland & Mar 4 to Mar 14 & Case report & Individual & 1 & $\mathrm{HCV}$ & LT recipient & $7 / 8$ \\
\hline $\begin{array}{l}\text { Fernández } \\
\text { (32) }\end{array}$ & Spain & Mar 5 to Apr 4 & Case series & Individual & 4 (out of 18 ) & $\begin{array}{c}\operatorname{HBV}(1), \operatorname{HCV}(2) \\
\operatorname{HBV} \& \operatorname{HCV}(1)\end{array}$ & OT recipients & $8 / 10$ \\
\hline Guan (33) & China & $\begin{array}{c}\text { Dec } 2019 \text { to Jan } \\
20\end{array}$ & Cross-sectional & Aggregate & 28 & HBV & $\begin{array}{l}\text { COVID-19 } \\
\text { patients }\end{array}$ & $8 / 9$ \\
\hline $\begin{array}{l}\text { Hammami } \\
(34)\end{array}$ & USA & Not reported & Case report & Individual & 1 & $\mathrm{HCV}$ & LT recipient & $7 / 8$ \\
\hline Huang (35) & China & Feb 1 to Mar 16 & Case report & Individual & 1 & HBV & LT recipient & $7 / 8$ \\
\hline $\begin{array}{l}\text { John Hann } \\
\text { (36) }\end{array}$ & UK & Mar 11 to Apr 12 & Case series & Individual & 1 (out of 3 ) & $\mathrm{HCV}$ & LT recipients & $5 / 10$ \\
\hline Kates (37) & USA & Not reported & Case series & Individual & 1 (out of 4$)$ & $\mathrm{HCV}$ & OT recipients & $9 / 10$ \\
\hline $\begin{array}{l}\text { Kreivenaite } \\
\text { (38) }\end{array}$ & Lithuania & $\begin{array}{c}\text { Mar } 16 \text { to Mar } \\
23\end{array}$ & Case report & Individual & 1 & $\mathrm{HCV}$ & Cirrhosis & $6 / 8$ \\
\hline Lee $^{\mathbf{b}}$ (39) & USA & Mar 18 to Apr 13 & Case series & Aggregate/Indivic & 2 (out of 28 ) & $\mathrm{HCV}$ & LT recipients & $10 / 10$ \\
\hline $\mathbf{L i}(40)$ & China & Jan 18 to Feb 26 & Case series & Individual & 7 & HBV & HBV patients & $10 / 10$ \\
\hline Liu (41) & China & Jan 23 to Feb 28 & Case report & Individual & 1 & HBV & LT recipient & $5 / 8$ \\
\hline Liu, J.(42) & China & Jan 1 to Apr 12 & Cross sectional & Aggregate & 21 & HBV & HBV patients & $9 / 9$ \\
\hline Loinaz (43) & Spain & Mar 15 to May 5 & Case series & Individual & 9 (out of 19) & $\operatorname{HBV}(2), \operatorname{HCV}(7)$ & LT recipients & $9 / 10$ \\
\hline Müller (45) & Austria & Mar 11 to Apr 9 & Case report & Individual & 1 & $\mathrm{HCV}(\mathrm{HIV}+)$ & HCV patient & $6 / 8$ \\
\hline Patrono (46) & Italy & Mar 5 to Apr 10 & Case series & Individual & 3 & $\operatorname{HBV}(2), \operatorname{HCV}(1)$ & LT recipients & $6 / 10$ \\
\hline Qi (47) & China & Jan 28 to Mar 11 & Case series & Individual & 1 (out of 3 ) & HBV & Cirrhosis & $7 / 10$ \\
\hline $\operatorname{Qin}(48)$ & China & Jan 14 to Mar 9 & Case report & Individual & 1 & HBV & LT recipient & $6 / 8$ \\
\hline Song (49) & China & $\begin{array}{l}\text { Dec } 2019 \text { to } \\
\text { Mar }\end{array}$ & Case report & Individual & 1 (out of 4$)$ & HBV & LT recipients & $5 / 10$ \\
\hline Waisberg (50) & Brazil & Mar to May & Case series & Individual & 1 (out 5 ) & $\mathrm{HCV}$ & LT recipients & $9 / 10$ \\
\hline Zhang (51) & China & Jan 24 to Feb 29 & Cross-sectional & Aggregate & 23 & HBV & HBV patients & $9 / 9$ \\
\hline Zhao (52) & China & Jan 25 to Jan 30 & Case report & Individual & 1 & $\mathrm{HCV}(\mathrm{HIV}+)$ & HCV patient & $6 / 8$ \\
\hline Zhong (53) & China & Jan 14 to Mar 12 & Case series & Individual & 1 (out of 2 ) & HBV & OT recipients & $6 / 10$ \\
\hline Zou (54) & China & Feb 1 to Mar 10 & Cross-sectional & Aggregate & 105 & HBV & HBV patients & $9 / 9$ \\
\hline
\end{tabular}

Abbreviations: LT: Liver Transplant, OT: Organ Transplant, KT: Kidney Transplant.

${ }^{\mathrm{a}}$ Study periods refer to 2020 unless otherwise specified.

${ }^{b}$ Lee, B et al. reported COVID-19 in 38 LT recipients, among whom 16 were HCV-positive and two were HBV-positive, but individual information was reported only for the deceased patients that included seven of total LT recipients and two of HCV-positive patients. For 14 HCV-positive and two HBV-positive patients, there was no individual information and we only knew that they were cured at the end of the follow-up.

were 69, 71, and 79-years-old. Two of them were female, and one was male. They had more than one comorbidity and were on immunosuppressive therapy due to their history of liver transplantation.

\subsection{COVID-19 Among Immunosuppressed Patients}

Based on the available individual data, the mean (SD) age of immunosuppressed patients was significantly higher than that of patients without immunosuppression (60.8 [11.7] vs. 49.9 [12]; P value $=0.001)$. About $85 \%(\mathrm{n}=$ 


\begin{tabular}{|c|c|c|}
\hline Characteristics (n Reported) & Cross-Sectional; No. (\%) & Case Series/Reports; No. (\%) \\
\hline Age $($ Mean \pm SD $)$ & $49.6 \pm 8.7[\mathrm{n}=87]$ & $50.8 \pm 13.5[\mathrm{n}=20]$ \\
\hline Sex & $\mathrm{n}=212$ & $n=20$ \\
\hline Male & $124(58.5)$ & $19(95)$ \\
\hline Female & $88(41.5)$ & $1(5)$ \\
\hline Cirrhosis & $\mathrm{n}=163$ & $\mathrm{n}=20$ \\
\hline Yes & $5(3.1)$ & $13(65)$ \\
\hline Liver transplantation & $\mathrm{n}=163$ & $\mathrm{n}=20$ \\
\hline Yes & $0(0)$ & $11(55)$ \\
\hline Immunosuppressive therapy & $\mathrm{n}=163$ & $\mathrm{n}=20$ \\
\hline Yes & $0(0)$ & $11(55)$ \\
\hline Elevated liver biochemistries & $\mathrm{n}=150$ & $\mathrm{n}=13$ \\
\hline ALT & $33(22.0)$ & $7(53.8)$ \\
\hline AST & $39(26.0)$ & $4(30.8)$ \\
\hline ALP & $3(2.0)$ & $1(7.7)$ \\
\hline GGT & $20(13.3)$ & $4(30.7)$ \\
\hline Co-morbidities (in addition to COVID-19/hepatitis) & $\mathrm{n}=164$ & $\mathrm{n}=15$ \\
\hline At least one morbidity & $57(34.7)$ & $4(26.7)$ \\
\hline Hypertension & $33(20.1)$ & $2(13.3)$ \\
\hline Chronic obstructive pulmonary disease & $3(1.8)$ & $2(13.3)$ \\
\hline Diabetes & $12(7.3)$ & $4(26.7)$ \\
\hline Cardiovascular disease & $8(4.9)$ & 0 \\
\hline Malignancy & $8(4.9)$ & 0 \\
\hline COVID-19 symptoms & $\mathrm{n}=168$ & $\mathrm{n}=20$ \\
\hline Fever & $130(77.4)$ & $17(86.0)$ \\
\hline Cough & $99(58.9)$ & $13(65.5)$ \\
\hline Dyspnea & $66(39.3)$ & $8(40.0)$ \\
\hline Headache & $5(3)$ & 0 \\
\hline Arthralgia/myalgia & $5(3)$ & $3(15.0)$ \\
\hline Fatigue & $58(34.5)$ & $2(10.0)$ \\
\hline Gastrointestinal symptoms & $23(13.7)$ & $5(25.0)$ \\
\hline Severity $^{a}$ & $\mathrm{n}=212$ & $\mathrm{n}=18$ \\
\hline Non-severe & $128(60.4)$ & $13(72.2)$ \\
\hline Severe & $84(39.6)$ & $5(27.8)$ \\
\hline Hospitalization & $\mathrm{n}=211$ & $\mathrm{n}=20$ \\
\hline Yes & $211(100)$ & $20(100)$ \\
\hline Intensive care unit admission & $\mathrm{n}=71$ & $\mathrm{n}=18$ \\
\hline Yes & $7(9.8)$ & $5(27.8)$ \\
\hline Death & $\mathrm{n}=211$ & $\mathrm{n}=20$ \\
\hline Yes & $10(4.7)$ & $3(15)$ \\
\hline
\end{tabular}

${ }^{\mathrm{a}}$ Mild cases reported as non-severe, and severe/critical cases reported as severe. 


\begin{tabular}{|c|c|}
\hline Characteristics (n Reported) & Case Series/Reports; No. (\%) \\
\hline Age $($ Mean \pm SD $)$ & $62.8 \pm 10.3[n=22]$ \\
\hline Sex & $\mathrm{n}=22$ \\
\hline Male & $16(72.8)$ \\
\hline Female & $6(27.3)$ \\
\hline Cirrhosis & $\mathrm{n}=21$ \\
\hline Yes & $20(95.2)$ \\
\hline Liver transplantation & $\mathrm{n}=22$ \\
\hline Yes & $20(90.9)$ \\
\hline Immunosuppressive therapy & $\mathrm{n}=22$ \\
\hline Yes & $20(90.9)$ \\
\hline Elevated liver biochemistries & $\mathrm{n}=13$ \\
\hline ALT & $5(38.5)$ \\
\hline AST & $5(38.5)$ \\
\hline ALP & $3(23.1)$ \\
\hline GGT & 3 of $9(33.3)$ \\
\hline Co-morbidities (in addition to COVID-19/hepatitis) & $\mathrm{n}=21$ \\
\hline At least one morbidity & $16(76.2)$ \\
\hline Hypertension & $12(57.1)$ \\
\hline Chronic obstructive pulmonary disease & $1(4.8)$ \\
\hline Diabetes & $8(38.1)$ \\
\hline Cardiovascular disease & $4(19)$ \\
\hline Malignancy & 0 \\
\hline COVID-19 symptoms & $\mathrm{n}=22$ \\
\hline Fever & $17(77.3)$ \\
\hline Cough & $14(63.6)$ \\
\hline Dyspnea & $9(40.9)$ \\
\hline Headache & $1(4.5)$ \\
\hline Arthralgia/myalgia & $4(18.2)$ \\
\hline Fatigue & $4(18.2)$ \\
\hline Gastrointestinal symptoms & $7(31.8)$ \\
\hline Severity $^{\mathbf{a}}$ & $\mathrm{n}=14$ \\
\hline Non-Severe & $11(78.6)$ \\
\hline Severe & $3(21.4)$ \\
\hline Hospitalization & $\mathrm{n}=22$ \\
\hline Yes & $19(86.4)$ \\
\hline Intensive care unit admission & $\mathrm{n}=14$ \\
\hline Yes & $3(21.4)$ \\
\hline Death $^{\text {b }}$ & $\mathrm{n}=36$ \\
\hline Yes & $3(8.3)$ \\
\hline
\end{tabular}

${ }^{\mathrm{a}}$ Mild cases reported as non-severe, and severe/critical cases reported as severe.

${ }^{\mathrm{b}}$ One of the cross-sectional studies reported COVID-19 in 38 LT recipients, among whom 16 were HCV-positive, and two were HBV-positive, but individual information was reported only for the deceased patients that included seven of total LT recipients and two of HCV-positive patients. For 14 HCV-positive and two HBV-positive patients, there was no individual information, and we only knew that they were cured at the end of the follow-up. Thus, we included them only for the calculation of the proportion of death. 
29) of immunosuppressed patients and $66 \%(n=31)$ of patients without immunosuppression were male ( $\mathrm{P}$ value $=$ $0.04)$. Overall, $51.5 \%(n=17)$ of patients with immunosuppression and $30 \%(n=12)$ of patients without immunosuppression had at least one comorbidity other than COVID-19 and hepatitis (P value $=0.07)$. Gastrointestinal symptoms were more common in immunosuppressed patients (32.2\% vs. $7.3 \%$; P value $=0.03$ ). The proportions of severe COVID19 in patients with and without immunosuppression were $33.3 \%$ and $30.4 \%$, respectively ( $P$ value $=0.7$ ). About $29 \%$ of patients with immunosuppression and $12.5 \%$ of patients without immunosuppression were admitted to the ICU (P value $=0.1$. Death happened in $17.6 \%$ of patients with immunosuppression and $6.4 \%$ of patients without immunosuppression $(\mathrm{P}$ value $=0.1$ ). See Table 4 for further details.

\subsection{Quality Assessment}

As shown in Table 1, quality assessment scores of the studies ranged from five to seven for case reports (out of eight possible points), five to 10 for case series (out of 10 possible points), and eight to nine for cross-sectional studies (out of nine possible points). Further details on the quality assessment tools and respective scores are presented in Supplementary File S3.

\section{Discussion}

We summarized data from 232 patients with SARS-CoV2 and $\mathrm{HBV}$ co-infection and 22 patients with SARS-CoV-2 and $\mathrm{HCV}$ co-infection. While our findings are relatively comparable with evidence from COVID-19 patients without hepatic comorbidities $(10,55)$, our data pointed to higher morbidity and mortality among COVID-19 patients living with HBV, HCV, or both. The most common COVID-19-related symptoms were fever, cough, dyspnea, fatigue, and gastrointestinal symptoms, which have also been common in COVID-19 patients without these co-infections (13, 56-58). Besides, ALT and AST were elevated in a considerable proportion of the patients, a finding that is consistent with estimates of a previous systematic review of earlier studies on liver manifestations among COVID-19 patients, where the pooled incidence of elevated liver chemistries among COVID-19 patients was reported as $23.1 \%$ (13).

Many studies have reported elevated liver biochemistries to be common among COVID-19 patients with and without hepatic comorbidities $(13,59,60)$; however, these findings should be interpreted with caution. First, it is unclear whether the liver damage observed among COVID-19 patients with HBV or HCV comorbidities is mainly due to the adverse impact of SARS-CoV-2 on hepatic cells or patients' pre-existing viral hepatitis. Second, corticosteroids that are commonly used as a treatment strategy in COVID-19 patients have been shown to increase the risk of hepatitis flare in HBV patients and might impact liver enzyme profiles among these patients (61-63). On the other hand, Chen et al. reported no difference in the level of liver function parameters between COVID-19infected patients and COVID-19-HBV co-infected patients (30). Kulkarni et al.'s meta-analysis of COVID-19-related liver manifestations reported patients with pre-existing chronic liver disease to have lower odds of developing severe COVID-19 (13). All of these rather equivocal findings highlight the importance of conducting well-controlled studies to fully understand the pathogenesis of SARSCoV-2 among HBV and HCV patients and determine the main underlying causes of elevated liver enzymes among these multimorbid patients to help improve clinical decision-making.

All of the patients in the SARS-CoV-2-HBV group and $86.4 \%$ of cases in the SARS-CoV-2-HCV group were hospitalized. While this finding might be interpreted as a higher risk of hospitalization among these multimorbid populations, it could also be reflective of the fact that the existing evidence is mainly based on, and indeed, skewed towards hospitalized severe COVID-19 patients with hepatic comorbidities. This was further evident in our finding that ICU admission in the SARS-COV-2-HBV co-infected group was estimated at $9.8 \%$ and $27.8 \%$ in cross-sectional and case series/report studies, respectively. Additionally, ICU admission in the SARS-COV-2-HCV co-infected group was estimated at $21.4 \%$.

The proportions of death were $4.7 \%$ and $15 \%$ among reported cases of SARS-CoV-2-HBV co-infection in crosssectional and case series/report studies, and $8.3 \%$ of reported cases in SARS-CoV-2-HCV co-infection. Given the high prevalence of multimorbidity among HBV and HCV patients and the fact that most patients included in this review were severe cases of hospitalized COVID-19 with a history of organ transplant, this finding should also be interpreted with caution when compared to the overall risk of mortality among COVID-19 patients, estimated to be around 2\% (10). Nonetheless, these findings are informative and suggest that among those who died, multimorbidity, older age, and male sex were common in comparison with all included patients.

Our findings of the impact of immunosuppression on COVID-19 severity are interesting, given the equivocal findings of different studies on the susceptibility of immunosuppressed patients to severe SARS-CoV-2 infection. While some assume a higher risk for the immunosuppressed population due to their systemic immunocompromised status $(21,64)$, others suggest that immunosuppression may protect against the hyperactivated immune response 
Table 4. Demographic and Clinical Characteristics of COVID-19 Infection in Hepatitis B and Hepatitis C Patients Included in Reviewed Studies Stratified by Immunosuppression (IS) Status

\begin{tabular}{|c|c|c|c|}
\hline Characteristics ( $n$ reported) & IS therapy, No. (\%) & No IS Therapy, No. (\%) & PValue \\
\hline Age $($ Mean $\pm S D)$ & $(\mathrm{n}=31) 60.8 \pm 11.7$ & $(\mathrm{n}=22) 49.9 \pm 12$ & 0.001 \\
\hline Sex & $\mathrm{n}=34$ & $\mathrm{n}=47$ & \\
\hline Male & $29(85.3)$ & $31(66)$ & 0.04 \\
\hline Female & $5(14.7)$ & $16(34)$ & \\
\hline Co-morbidities (in addition to COVID-19 and hepatitis) & $\mathrm{n}=33$ & $\mathrm{n}=40$ & \\
\hline At least one morbidity & $17(51.5)$ & $12(30)$ & 0.09 \\
\hline COVID-19 symptoms & $\mathrm{n}=34$ & $\mathrm{n}=47$ & \\
\hline Fever & $27(79.4)$ & $29(61.7)$ & 0.1 \\
\hline Cough & $20(58.8)$ & $23(48.9)$ & 0.3 \\
\hline Dyspnea & $13(38.2)$ & $9(19.1)$ & 0.09 \\
\hline Headache & $1(2.9)$ & $2(4.2)$ & 0.3 \\
\hline Arthralgia/myalgia & $6(17.6)$ & $4(8.5)$ & 0.2 \\
\hline Fatigue & $6(17.6)$ & $9(19.1)$ & 0.1 \\
\hline Gastrointestinal symptoms & $11(32.3)$ & $3(7.3)$ & 0.03 \\
\hline Severity & $\mathrm{n}=24$ & $\mathrm{n}=46$ & \\
\hline Non-severe & $16(66.7)$ & $32(69.6)$ & 0.7 \\
\hline Severe & $8(33.3)$ & $14(30.4)$ & \\
\hline Hospitalization & $\mathrm{n}=34$ & $\mathrm{n}=47$ & 0.07 \\
\hline Yes & $31(91.2)$ & $47(100)$ & \\
\hline Intensive care unit admission & $\mathrm{n}=24$ & $\mathrm{n}=32$ & 0.1 \\
\hline Yes & $7(29.2)$ & $4(12.5)$ & \\
\hline Death & $\mathrm{n}=34$ & $\mathrm{n}=47$ & 0.1 \\
\hline Yes & $6(17.6)$ & $3(6.4)$ & \\
\hline
\end{tabular}

$(65,66)$. We found that the proportions of severe COVID-19 cases, admission to the ICU, and death were higher among patients with immunosuppression than in patients without immunosuppression; however, these differences were not statistically significant. These findings are not conclusive and should be interpreted with an eye for the limited sample size in the studies, the observational nature of the studies, the non-matched nature of the comparisons, and the fact that these differences could be due to the immunosuppressed group being more likely to be older, male, and have organ transplants, advanced liver disease, and other extrahepatic comorbidities.

We acknowledge the limitations of our study. First, while most COVID-19 patients are asymptomatic, the available evidence that informed this review included mostly hospitalized patients and was skewed towards more severe patients often with a history of organ transplant and advanced liver disease; therefore, our findings cannot be generalizable to all patients living with COVID-19 and HBV or
HCV comorbidities. Second, due to the descriptive design of the included studies and lack of a comparison group, we could not identify factors associated with SARS-CoV-2$\mathrm{HBV}$ or HCV co-infections. Third, most of the included studies were case series and had a small sample size. Therefore, the accurate prevalence of COVID-19 and its manifestations among HBV or HCV subpopulations remains unknown without a population-based survey of patients with these comorbidities. Lastly, given the growing nature of the pandemic and the overwhelmed healthcare systems worldwide, viral hepatitis manifestations may be underrecorded or overlooked during clinical visits, leading to the underestimation of the scope of hepatic manifestations among COVID-19 patients with HBV and HCV comorbidities.

\subsection{Conclusions}

Despite the limitations of the existing evidence, our data suggest that liver enzyme abnormalities and acute 
hepatic injuries may be common among COVID-19 patients with HBV and HCV comorbidities. Therefore, these paraclinical profiles should be monitored and examined during clinical visits. While understanding the pathogenesis of SARS-CoV-2 requires further investigations, a careful assessment of hepatic manifestations upon admission could help reduce the multimorbidity among HBV or HCV patients and lead to more favorable health outcomes among COVID-19 patients.

\section{Supplementary Material}

Supplementary material(s) is available here [To read supplementary materials, please refer to the journal website and open PDF/HTML].

\section{Acknowledgments}

The authors did not receive any funding for this study. MK is a member of the Pierre Elliott Trudeau Foundation's COVID-19 impact committee and is supported by the Pierre Elliott Trudeau Foundation Doctoral Scholarship. MS is supported by a Canadian Institute of Health Research (CIHR) Postdoctoral Scholarship.

\section{Footnotes}

Authors' Contribution: Conceptualization: HM, HAS, HES, and MK, Screening: HM and MV, Data Extraction: HM, MV, and MK, Data Analysis: HM, MS, MD, MK, and HES, Manuscript Drafting: HM and MK, Review and Editing: HM, MV, MS, MD, HAS, HES, and MK.

Conflict of Interests: None declared.

Funding/Support: None declared.

\section{References}

1. Zhu N, Zhang D, Wang W, Li X, Yang B, Song J, et al. A Novel Coronavirus from Patients with Pneumonia in China, 2019. N Engl J Med 2020;382(8):727-33. doi: 10.1056/NEJMoa2001017. [PubMed: 31978945]. [PubMed Central: PMC7092803].

2. WHO. WHO Coronavirus Disease (COVID-19) Dashboard. 2020. Available from: https://covid19.who.int/.

3. Wang L, He W, Yu X, Hu D, Bao M, Liu H, et al. Coronavirus disease 2019 in elderly patients: Characteristics and prognostic factors based on 4-week follow-up. J Infect. 2020;80(6):639-45. doi: 10.1016/j.jinf.2020.03.019. [PubMed: 32240670]. [PubMed Central: PMC7118526].

4. Guo W, Li M, Dong Y, Zhou H, Zhang Z, Tian C, et al. Diabetes is a risk factor for the progression and prognosis of COVID-19. Diabetes Metab Res Rev. 2020. e3319. doi:10.1002/dmrr.3319. [PubMed: 32233013]. [PubMed Central: PMC7228407].
5. Mostaza JM, Garcia-Iglesias F, Gonzalez-Alegre T, Blanco F, Varas M, Hernandez-Blanco C, et al. Clinical course and prognostic factors of COVID-19 infection in an elderly hospitalized population. Arch Gerontol Geriatr. 2020;91:104204. doi: 10.1016/j.archger.2020.104204. [PubMed: 32771883]. [PubMed Central: PMC7383171].

6. Foldi M, Farkas N, Kiss S, Zadori N, Vancsa S, Szako L, et al. Obesity is a risk factor for developing critical condition in COVID-19 patients: A systematic review and meta-analysis. Obes Rev. 2020;21(10). e13095. doi: 10.1111/obr.13095. [PubMed: 32686331]. [PubMed Central: PMC7404429].

7. Fang X, Li S, Yu H, Wang P, Zhang Y, Chen Z, et al. Epidemiological, comorbidity factors with severity and prognosis of COVID-19: a systematic review and meta-analysis. Aging (Albany NY). 2020;12(13):12493503. doi: 10.18632/aging.103579. [PubMed: 32658868]. [PubMed Central: PMC7377860].

8. Figliozzi S, Masci PG, Ahmadi N, Tondi L, Koutli E, Aimo A, et al. Predictors of adverse prognosis in COVID-19: A systematic review and metaanalysis. Eur J Clin Invest. 2020;50(10). e13362. doi: 10.1111/eci.13362. [PubMed: 32726868].

9. Goyal P, Choi JJ, Pinheiro LC, Schenck EJ, Chen R, Jabri A, et al. Clinical Characteristics of Covid-19 in New York City. $N$ Engl J Med. 2020;382(24):2372-4. doi: 10.1056/NEJMc2010419. [PubMed: 32302078]. [PubMed Central: PMC7182018].

10. Khalili M, Karamouzian M, Nasiri N, Javadi S, Mirzazadeh A, Sharifi H. Epidemiological characteristics of COVID-19: a systematic review and meta-analysis. Epidemiol Infect. 2020;148. e130. doi: 10.1017/S0950268820001430. [PubMed: 32594937]. [PubMed Central: PMC7343974].

11. Wander P, Epstein M, Bernstein D. COVID-19 Presenting as Acute Hepatitis. Am J Gastroenterol. 2020;115(6):941-2. doi: 10.14309/ajg.0000000000000660. [PubMed: 32301760]. [PubMed Central: PMC7172489].

12. Alqahtani SA, Schattenberg JM. Liver injury in COVID-19: The current evidence. United European Gastroenterol J. 2020;8(5):509-19. doi 10.1177/2050640620924157. [PubMed: 32450787]. [PubMed Central: PMC7268949].

13. Kulkarni AV, Kumar P, Tevethia HV, Premkumar M, Arab JP, Candia $\mathrm{R}$, et al. Systematic review with meta-analysis: liver manifestations and outcomes in COVID-19. Aliment Pharmacol Ther. 2020;52(4):58499. doi: 10.1111/apt.15916. [PubMed: 32638436]. [PubMed Central: PMC7361465].

14. Mehta P, McAuley DF, Brown M, Sanchez E, Tattersall RS, Manson JJ. COVID-19: consider cytokine storm syndromes and immunosuppression. Lancet. 2020;395(10229):1033-4. doi: 10.1016/s01406736(20)30628-0.

15. Kunutsor SK, Laukkanen JA. Hepatic manifestations and complications of COVID-19: A systematic review and meta-analysis. I Infect. 2020;81(3):e72-4. doi: 10.1016/j.jinf.2020.06.043. [PubMed: 32579984] [PubMed Central: PMC7306105].

16. Huang C, Wang Y, Li X, Ren L, Zhao J, Hu Y, et al. Clinical features of patients infected with 2019 novel coronavirus in Wuhan, China. Lancet 2020;395(10223):497-506. doi:10.1016/s0140-6736(20)30183-5.

17. Guan WJ, Ni ZY, Hu Y, Liang WH, Ou CQ, He JX, et al. Clinical Characteristics of Coronavirus Disease 2019 in China. N Engl J Med. 2020;382(18):1708-20. doi: 10.1056/NEJMoa2002032. [PubMed: 32109013]. [PubMed Central: PMC7092819].

18. Khinda J, Janjua NZ, Cheng S, van den Heuvel ER, Bhatti P, Darvishian M. Association between markers of immune response at hospital admission and COVID-19 disease severity and mortality: A meta-analysis and meta-regression. J Med Virol. 2021;93(2):107898. doi: 10.1002/jmv.26411. [PubMed: 32776551]. [PubMed Central: PMC7436507].

19. Fan Z, Chen L, Li J, Cheng X, Yang J, Tian C, et al. Clinical Features of COVID-19-Related Liver Functional Abnormality. Clin Gastroenterol Hepatol. 2020;18(7):1561-6. doi: 10.1016/j.cgh.2020.04.002. [PubMed: 32283325]. [PubMed Central: PMC7194865]. 
20. Cai Q, Huang D, Yu H, Zhu Z, Xia Z, Su Y, et al. COVID-19: Abnormal liver function tests. J Hepatol. 2020;73(3):566-74. doi: 10.1016/j.jhep.2020.04.006. [PubMed: 32298767]. [PubMed Central: PMC7194951].

21. Zhang C, Shi L, Wang F. Liver injury in COVID-19: management and challenges. Lancet Gastroenterol Hepatol. 2020;5(5):428-30. doi: 10.1016/s2468-1253(20)30057-1.

22. Hernandez Mdel P, Martin P, Simkins J. Infectious Complications After Liver Transplantation. Gastroenterol Hepatol (N Y). 2015;11(11):74153. [PubMed: 27134589]. [PubMed Central: PMC4849501].

23. Razavi-Shearer D, Gamkrelidze I, Nguyen MH, Chen D, Van Damme P, Abbas Z, et al. Global prevalence, treatment, and prevention of hepatitis B virus infection in 2016: a modelling study. Lancet Gastroenterol Hepatol. 2018;3(6):383-403. doi:10.1016/s2468-1253(18)30056-6.

24. Blach S, Zeuzem S, Manns M, Altraif I, Duberg A, Muljono DH, et al. Global prevalence and genotype distribution of hepatitis $C$ virus infection in 2015: a modelling study. Lancet Gastroenterol Hepatol. 2017;2(3):161-76. doi:10.1016/s2468-1253(16)30181-9.

25. Pressman P, Clemens R, Sahu S, Hayes AW. A review of methanol poisoning: a crisis beyond ocular toxicology. Cutan Ocul Toxicol. 2020;39(3):173-9. doi: 10.1080/15569527.2020.1768402. [PubMed: 32396759].

26. Mirzaei H, McFarland W, Karamouzian M, Sharifi H. COVID-19 Among People Living with HIV: A Systematic Review. AIDS Behav. 2020. doi: 10.1007/s10461-020-02983-2. [PubMed: 32734438]. [PubMed Central: PMC7391049].

27. Joanna Briggs Institute. JBI's Critical Appraisal Tools. 2020. Available from: https://joannabriggs.org/critical-appraisal-tools.

28. Aldhaleei WA, Alnuaimi A, Bhagavathula AS. COVID-19 Induced Hepatitis B Virus Reactivation: A Novel Case From the United Arab Emirates. Cureus. 2020;12(6). e8645. doi: 10.7759/cureus.8645. [PubMed: 32550096]. [PubMed Central: PMC7296884].

29. Chen X, Jiang Q, Ma Z, Ling J, Hu W, Cao Q, et al. Clinical Characteristics of Hospitalized Patients with SARS-CoV-2 and Hepatitis B Virus Co-infection. Virol Sin. 2020. doi: 10.1007/s12250-020-00276-5.

30. Chen L, Huang S, Yang J, Cheng X, Shang Z, Lu H, et al. Clinical characteristics in patients with SARS-CoV-2/HBV co-infection. J Viral Hepat. 2020;27(12):1504-7. doi: 10.1111/jvh.13362. [PubMed: 32668494]. [PubMed Central: PMC7404861].

31. De Gottardi A, Fratila C, Bertoli R, Cerny A, Magenta L, Gianella P, et al. Clinical characteristics and management of a liver transplanted patient admitted with SARS-CoV-2 infection. Clin Res Hepatol Gastroenterol. 2020;44(6):e141-4. doi: 10.1016/j.clinre.2020.05.014. [PubMed: 32565199]. [PubMed Central: PMC7284277].

32. Fernandez-Ruiz M, Andres A, Loinaz C, Delgado JF, Lopez-Medrano F, San Juan R, et al. COVID-19 in solid organ transplant recipients: A single-center case series from Spain. Am JTransplant. 2020;20(7):184958. doi: 10.1111/ajt.15929. [PubMed: 32301155].

33. Guan W, Liang W, Zhao Y, Liang H, Chen Z, Li Y, et al. Comorbidity and its impact on 1,590 patients with COVID-19 in China: A Nationwide Analysis. medRxiv. 2020. doi: 10.1101/2020.02.25.20027664.

34. Hammami MB, Garibaldi B, Shah P, Liu G, Jain T, Chen PH, et al. Clinical course of COVID-19 in a liver transplant recipient on hemodialysis and response to tocilizumab therapy: A case report. Am J Transplant. 2020;20(8):2254-9. doi: 10.1111/ajt.15985. [PubMed: 32359210]. [PubMed Central: PMC7267667].

35. Huang JF, Zheng KI, George J, Gao HN, Wei RN, Yan HD, et al. Fatal outcome in a liver transplant recipient with COVID-19. Am J Transplant. 2020;20(7):1907-10. doi: 10.1111/ajt.15909. [PubMed: 32277591]. [PubMed Central: PMC7262021].

36. John Hann A, Lembach H, McKay SC, Perrin M, Isaac J, Oo YH, et al. Controversies regarding shielding and susceptibility to COVID-19 disease in liver transplant recipients in the United Kingdom. Transpl Infect Dis. 2020;22(5). e13352. doi: 10.1111/tid.13352. [PubMed: 32500939]. [PubMed Central: PMC7300473].

37. Kates OS, Fisher CE, Stankiewicz-Karita HC, Shepherd AK, Church EC,
Kapnadak SG, et al. Earliest cases of coronavirus disease 2019 (COVID19) identified in solid organ transplant recipients in the United States. Am J Transplant. 2020;20(7):1885-90. doi: 10.1111/ajt.15944. [PubMed: 32330356]. [PubMed Central: PMC7264737].

38. Kreivenaite E, Gedgaudas R, Valantiene I, Mickiene A, Kupcinskas J. COVID-19 in a Patient with Liver Cirrhosis. J Gastrointestin Liver Dis. 2020;29(2):263-6. doi: 10.15403/jgld-2440. [PubMed: 32530994].

39. Lee BT, Perumalswami PV, Im GY, Florman S, Schiano TD, Cobe Study Group. COVID-19 in Liver Transplant Recipients: An Initial Experience From the US Epicenter. Gastroenterology. 2020;159(3):1176-1178 e2. doi: 10.1053/j.gastro.2020.05.050. [PubMed: 32442561]. [PubMed Central: PMC7237372].

40. Li Y, Li C, Wang J, Zhu C, Zhu L, Ji F, et al. A case series of COVID-19 patients with chronic hepatitis B virus infection. J Med Virol. 2020;92(11):2785-91. doi: 10.1002/jmv.26201. [PubMed: 32558945]. [PubMed Central: PMC7323302].

41. Liu B, Wang Y, Zhao Y, Shi H, Zeng F, Chen Z. Successful treatment of severe COVID-19 pneumonia in a liver transplant recipient. Am J Transplant. 2020;20(7):1891-5. doi: 10.1111/ajt.15901. [PubMed: 32243673].

42. Liu J, Wang T, Cai Q, Sun L, Huang D, Zhou G, et al. Longitudinal changes of liver function and hepatitis B reactivation in COVID-19 patients with pre-existing chronic hepatitis B virus infection. Hepatol Res. 2020;50(11):1211-21. doi: 10.1111/hepr.13553. [PubMed: 32761993]. [PubMed Central: PMC7436737].

43. Loinaz C, Marcacuzco A, Fernandez-Ruiz M, Caso O, Cambra F, San Juan R, et al. Varied clinical presentation and outcome of SARS-CoV2 infection in liver transplant recipients: Initial experience at a single center in Madrid, Spain. Transpl Infect Dis. 2020;22(5). e13372. doi: 10.1111/tid.13372. [PubMed: 32562561]. [PubMed Central: PMC7323090].

44. Machado DJB, Ianhez LE. COVID-19 pneumonia in kidney transplant recipients-Where we are? Transpl Infect Dis. 2020;22(5). e13306. doi: 10.1111/tid.13306. [PubMed: 32364677]. [PubMed Central: PMC7261981].

45. Muller H, Kniepeiss D, Stauber R, Schrem H, Rauter M, Krause R, et al. Recovery from COVID-19 following hepatitis C, human immunodeficiency virus infection, and liver transplantation. Am J Transplant. 2020;20(11):3255-6. doi: 10.1111/ajt.16107. [PubMed: 32492753]. [PubMed Central: PMC7300671].

46. Patrono D, Lupo F, Canta F, Mazza E, Mirabella S, Corcione S, et al. Outcome of COVID-19 in liver transplant recipients: A preliminary report from Northwestern Italy. Transpl Infect Dis. 2020;22(5). e13353. doi: 10.1111/tid.13353. [PubMed: 32500942]. [PubMed Central: PMC7300527].

47. Qi X, Wang J, Li X, Wang Z, Liu Y, Yang H, et al. Clinical course of COVID19 in patients with pre-existing decompensated cirrhosis: initial report from China. Hepatol Int. 2020;14(4):478-82. doi: 10.1007/s12072020-10051-z. [PubMed: 32440857]. [PubMed Central: PMC7242176].

48. Qin J, Wang H, Qin X, Zhang P, Zhu L, Cai J, et al. Perioperative Presentation of COVID-19 Disease in a Liver Transplant Recipient. Hepatology. 2020;72(4):1491-3. doi: 10.1002/hep.31257. [PubMed: 32220017].

49. Song SH, Chen TL, Deng LP, Zhang YX, Mo PZ, Gao SC, et al. Clinical characteristics of four cancer patients with SARS-CoV-2 infection in Wuhan, China. Infect Dis Poverty. 2020;9(1):82. doi: 10.1186/s40249-02000707-1. [PubMed: 32616030]. [PubMed Central: PMC7330531].

50. Waisberg DR, Abdala E, Nacif LS, Haddad LB, Ducatti L, Santos VR, et al. Liver transplant recipients infected with SARS-CoV-2 in the early postoperative period: Lessons from a single center in the epicenter of the pandemic. Transpl Infect Dis. 2020. e13418. doi: 10.1111/tid.13418. [PubMed: 32667716]. [PubMed Central: PMC7404440].

51. Zhang B, Huang W, Zhang S. Clinical Features and Outcomes of Coronavirus Disease 2019 (COVID-19) Patients With Chronic Hepatitis B Virus Infection. Clin Gastroenterol Hepatol. 2020;18(11):2633-7. doi: 10.1016/j.cgh.2020.06.011. [PubMed: 32553905].

52. Zhao J, Liao X, Wang H, Wei L, Xing M, Liu L, et al. Early Virus Clearance and Delayed Antibody Response in a Case of Coronavirus Disease 2019 (COVID-19) With a History of Coinfection With Human Immunodeficiency Virus Type 1 and Hepatitis C Virus. Clin Infect 
Dis. 2020;71(16):2233-5. doi: 10.1093/cid/ciaa408. [PubMed: 32270178]. [PubMed Central: PMC7184426].

53. Zhong Z, Zhang Q, Xia H, Wang A, Liang W, Zhou W, et al. Clinical characteristics and immunosuppressant management of coronavirus disease 2019 in solid organ transplant recipients. Am J Transplant. 2020;20(7):1916-21. doi: 10.111//ajt.15928. [PubMed: 32282986]. [PubMed Central: PMC7262295].

54. Zou X, Fang M, Li S, Wu L, Gao B, Gao H, et al. Characteristics of Liver Function in Patients With SARS-CoV-2 and Chronic HBV Coinfection. Clin Gastroenterol Hepatol. 2020. doi: 10.1016/j.cgh.2020.06.017. [PubMed: 32553907]. [PubMed Central: PMC7294291].

55. Rodriguez-Morales AJ, Cardona-Ospina JA, Gutierrez-Ocampo E, Villamizar-Pena R, Holguin-Rivera Y, Escalera-Antezana JP, et al. Clinical, laboratory and imaging features of COVID-19: A systematic review and meta-analysis. Travel Med Infect Dis. 2020;34:101623. doi: 10.1016/j.tmaid.2020.101623. [PubMed: 32179124]. [PubMed Central: PMC7102608].

56. Hu Y, Sun J, Dai Z, Deng H, Li X, Huang Q, et al. Prevalence and severity of corona virus disease 2019 (COVID-19): A systematic review and meta-analysis. $J$ Clin Virol. 2020;127:104371. doi: 10.1016/j.jcv.2020.104371. [PubMed: 32315817]. [PubMed Central: PMC7195434].

57. Chen N, Zhou M, Dong X, Qu J, Gong F, Han Y, et al. Epidemiological and clinical characteristics of 99 cases of 2019 novel coronavirus pneumonia in Wuhan, China: a descriptive study. Lancet. 2020;395(10223):507-13. doi: 10.1016/S0140-6736(20)30211-7. [PubMed: 32007143]. [PubMed Central: PMC7135076].

58. Zhu J, Ji P, Pang J, Zhong Z, Li H, He C, et al. Clinical characteristics of 3062 COVID-19 patients: A meta-analysis. J Med Virol.2020;92(10):190214. doi: 10.1002/jmv.25884. [PubMed: 32293716]. [PubMed Central: PMC7262119].

59. Yang X, Yu Y, Xu J, Shu H, Xia J, Liu H, et al. Clinical course and outcomes of critically ill patients with SARS-CoV-2 pneumonia in Wuhan, China: a single-centered, retrospective, observational study. Lancet Respir Med. 2020;8(5):475-81. doi: 10.1016/S2213-2600(20)300795. [PubMed: 32105632]. [PubMed Central: PMC7102538].

60. Xu X, Wu X, Jiang X, Xu K, Ying L, Ma C, et al. Clinical findings in a group of patients infected with the 2019 novel coronavirus (SARS-Cov2) outside of Wuhan, China: retrospective case series. bmj. 2020;368.

61. Shang L, Zhao J, Hu Y, Du R, Cao B. On the use of corticosteroids for 2019-nCoV pneumonia. Lancet. 2020;395(10225):683-4. doi: 10.1016/S0140-6736(20)30361-5. [PubMed: 32122468]. [PubMed Central: PMC7159292].

62. Wong GL, Wong VW, Yuen BW, Tse YK, Yip TC, Luk HW, et al. Risk of hepatitis B surface antigen seroreversion after corticosteroid treatment in patients with previous hepatitis B virus exposure. J Hepatol. 2020;72(1):57-66. doi: 10.1016/j.jhep.2019.08.023. [PubMed: 31499132].

63. Hwang JP, Lok AS. Management of patients with hepatitis B who require immunosuppressive therapy. Nat Rev Gastroenterol Hepatol. 2014;11(4):209-19. doi: 10.1038/nrgastro.2013.216. [PubMed: 24247262]. [PubMed Central: PMC4170710].

64. Jin X, Lian JS, Hu JH, Gao J, Zheng L, Zhang YM, et al. Epidemiological, clinical and virological characteristics of 74 cases of coronavirusinfected disease 2019 (COVID-19) with gastrointestinal symptoms. Gut. 2020;69(6):1002-9. doi: 10.1136/gutjnl-2020-320926. [PubMed: 32213556]. [PubMed Central: PMC7133387].

65. D'Antiga L. Coronaviruses and Immunosuppressed Patients: The Facts During the Third Epidemic. Liver Transpl. 2020;26(6):832-4. doi: 10.1002/It.25756. [PubMed: 32196933].

66. Boettler T, Newsome PN, Mondelli MU, Maticic M, Cordero E, Cornberg $\mathrm{M}$, et al. Care of patients with liver disease during the COVID19 pandemic: EASL-ESCMID position paper. JHEP Rep. 2020;2(3):100113. doi: 10.1016/j.jhepr.2020.100113. [PubMed:32289115].[PubMed Central: PMC7128473]. 